\title{
Germinação de espécies forrageiras na presença de cádmio, cobre e chumbo
}

\author{
Germination of forage species in the presence of cadmium, copper and lead \\ Kathleen Steiner Rosniecek, Mari Lucia Campos*, Cileide Maria Medeiros Coelho, David José \\ Miquelluti, Emili Louise Diconcili Schutz
}

Universidade do Estado de Santa Catarina, Lages, SC, Brasil. *Autor para correspondência: mari.campos@udesc.br

Submissão: 19/07/2019 / Aceite: 22/06/2020

\begin{abstract}
RESUMO
Solo contaminado com elementos-traço tem necessidade de introduzir espécies tolerantes e de crescimento rápido. O objetivo deste estudo foi avaliar a germinação das espécies forrageiras Brachiaria humidicola cv. Tupi, Panicum maximum cultivares Aruana e Tanzânia na presença dos elementos-traço cádmio $(\mathrm{Cd})$, cobre $(\mathrm{Cu})$ e chumbo $(\mathrm{Pb})$. O experimento foi conduzido no Laboratório para Análise de Sementes (CAV-UDESC), os testes foram conduzidos na ausência dos elementos (testemunha - $0 \mathrm{mg}$ $\mathrm{L}^{-1}$ ), e nas concentrações de 3, 180 e $200 \mathrm{mg} \mathrm{L}^{-1}$ para $\mathrm{Cd}, \mathrm{Pb}$ e Cu, respectivamente. Foram calculados a porcentagem de germinação (G), Índice de Velocidade de Germinação (IVG), Vigor (V) e Índice de tolerância para parte aérea (PA) e raiz (RA). A presença do Cu inibiu a germinação, emissão de raiz e parte aérea da espécie $P$. maximum cv. Aruana, bem como o índice de vigor foi afetado pela presença do Cu para as espécies $P$. maximum cv. Tanzânia e $B$. humidicola cv. Tupi. A porcentagem de germinação, índice de velocidade de germinação e comprimento de parte aérea das três espécies estudadas foram afetadas pela presença do $\mathrm{Cd}$. A presença do $\mathrm{Pb}$ afetou o comprimento de parte aérea e raiz, e índice de vigor para $P$. maximum cv. Aruana e $P$. maximum cv. Tanzânia. A ordem decrescente de sensibilidade das espécies na presença de $\mathrm{Cd}$ e $\mathrm{Pb}$ foi $P$. maximum cv. Aruana $>P$. maximum cv. Tanzânia $>B$. humidicola cv. Tupi.
\end{abstract}

PALAVRAS-CHAVE: elementos-traço, toxicidade, Brachiaria, Panicum.

\begin{abstract}
Soil contaminated with trace elements needs to introduce tolerant species and rapid growth. The objective of this study was to evaluate the germination of forage species Brachiaria humidicola cv. Tupi, Panicum maximum cultivars Aruana and Tanzania in the presence of trace elements cadmium (Cd), copper $(\mathrm{Cu})$ and lead $(\mathrm{Pb})$. The experiment was conducted in the Laboratory for Seed Analysis (CAV-UDESC), the tests were conducted in the absence of the elements (control $-0 \mathrm{mg} \mathrm{L}^{-1}$ ), and in the concentrations of 3 , 180 and $200 \mathrm{mg} \mathrm{L}^{-1}$ for $\mathrm{Cd}, \mathrm{Pb}$ and $\mathrm{Cu}$ respectively. Germination percentage (G), Germination Speed Index (GSI), Vigor (V) and tolerance index for aerial parts (AP) and root (R) were calculated. The presence of $\mathrm{Cu}$ inhibited the germination, root emission and aerial part of the species $P$. maximum $\mathrm{cv}$. Aruana, as for vigor index was affected by the presence of $\mathrm{Cu}$ for the species $P$. maximum cv. Tanzânia and $B$. humidicola cv. Tupi. The percentage of germination, germination speed index and shoot length of the three species studied were affected by the presence of $\mathrm{Cd}$. The presence of $\mathrm{Pb}$ affected shoot length and root length, and vigor index for $P$. maximum cv. Aruana and $P$. maximum cv. Tanzânia. The decreasing order of species sensitivity in the presence of $\mathrm{Cd}$ and $\mathrm{Pb}$ was $P$. maximum $\mathrm{cv}$. Aruana $>P$. maximum $\mathrm{cv}$. Tanzânia > B. humidicola cv. Tupi.
\end{abstract}

KEYWORDS: trace elements, toxicity, Brachiaria, Panicum.

\section{INTRODUÇÃO}

$\mathrm{Na}$ exploração de recursos minerais um componente de grande importância é a recuperação das áreas degradadas, em especial no processo de mineração de superfície onde apresentam grandes impactos sobre o solo e a paisagem. As atividades de exploração mineral devem ser planejadas e sua recuperação deve fazer parte do plano de práticas e conservação do solo, preservando assim o potencial produtivo do solo (YADA et al. 2015). 
Para a restauração de solos contaminados com elementos-traço uma das técnicas é a fitorremediação, onde são usadas plantas tolerantes que removam e acumulam elementos-traço em seus tecidos (MIDHAT et al. 2019). As plantas usadas na fitorremediação melhoram a fertilidade do solo, aumentam o conteúdo de matéria orgânica. Sendo já comprovada que é uma técnica mais ecológica e econômica que as alternativas físico e químicas convencionais (ÁLVAREZ-MATEOS et al. 2019).

As interações do sistema solo-planta são de natureza complexa e a disponibilidade dos elementostraço para as plantas podem variar devido a diversos fatores que atuam na absorção dos elementos-traço em plantas. Esses fatores dependem das propriedades do solo tais como composição química do solo, granulometria, teor de matéria orgânica, capacidade de troca catiônica, $\mathrm{pH}$ do solo ou da extensão do sistema radicular (SANTOS et al. 2005, KABATA-PENDIAS 2011).

Tem aumentado consideravelmente nos últimos anos o uso de gramíneas forrageiras para fitorremediação de elementos-traço, uma vez que, estas plantas mostram um crescimento rápido, um vasto sistema radicular (o que aumenta a captação de elementos-traço), e produção de massa seca elevada (CHEN et al. 2014, LAMBRECHTS et al. 2014).

Portanto, as gramíneas têm importância fundamental ajudando na recuperação, proteção e revitalização do solo, apresentando rápido crescimento, exigência em fertilidade relativamente baixa, alta capacidade de perfilhamento e sistema radicular fasciculado, produzindo estolões e rizomas. Este conjunto de atributos faz com que as gramíneas sejam apropriadas para a recomposição e recuperação das áreas degradadas com elementos-traço (PEREIRA 2006).

Entre as gramíneas, a Brachiaria spp. destaca-se pela quantidade de matéria seca produzida, pelo fácil cultivo e pela sua adaptação sob diferentes solos, entretanto, poucos são os estudos com este gênero na presença da contaminação por elementos-traço. Gramíneas têm um melhor estabelecimento em áreas contaminadas com elementos-traço, com facilidade no desenvolvimento, rápido crescimento, ajudando na ciclagem de nutrientes, aumentando o teor de matéria orgânica e melhorando a cobertura do solo (BORGES et al. 2016). Para Panicum maximum Jacq., as cultivares disponíveis comercialmente são basicamente adaptadas a solos profundos, bem drenados e de boa fertilidade (CORREA \& SANTOS 2003). A cultivar Aruana apresenta alta produtividade de forragem (SOUZA et al. 2018), com 35 a $40 \%$ da produção anual ocorrendo no inverno. Possui propagação por sementes, com formação rápida da pastagem, e grande potencial e rapidez no perfilhamento, com excelente capacidade de cobertura do solo, que auxiliam no controle da erosão (CORREIA \& PERUSSI 2015). Já a cultivar Tanzânia apresenta elevado potencial de produção e valor nutritivo e alta resposta à adubação (GONÇALVES \& BORGES 2006).

A germinação é uma das fases mais importantes da semente, sendo um processo sensível a elementos-traço comparando com outros estágios do desenvolvimento da planta. Portanto, a avaliação da germinação pode ser útil na seleção de gramíneas para fitorremediação, entretanto, poucas são as informações sobre como elas são afetadas na presença de altas concentrações de elementos-traço (MADEJÓN et al. 2015). Diferentes elementos-traço em diferentes doses possibilitam diferentes graus de toxicidade podendo ou não inibir a germinação (KRANNER \& COLVILLE 2011).

Neste contexto, o presente estudo tem como objetivo avaliar a germinação e a tolerância das espécies Brachiaria humidicola cv. BRS Tupi e Panicum maximum cultivares Aruana e Tanzânia na presença dos elementos-traço $\mathrm{Cd}$, $\mathrm{Cu}$ e $\mathrm{Pb}$.

\section{MATERIAL E MÉTODOS}

O experimento foi conduzido no Laboratório de Análise de Sementes (LAS) do Centro de Ciências Agroveterinárias (CAV-UDESC), Lages, SC. Foram utilizadas sementes puras de Panicum maximum cv. Aruana, Panicum maximum cv. BRS Tanzânia, Brachiaria humidicola cv. BRS Tupi, sendo a primeira proveniente da Empresa Sementes Gasparim e as duas últimas da EMBRAPA. Os percentuais de pureza das sementes foram realizados pelas Empresas de origem e encontram-se na Tabela 1. As sementes foram acondicionadas em local seco e sem umidade.

Antes do início de todos os testes, foi realizada a superação da dormência e o tratamento sanitário. Para a superação de dormência foi realizado o pré-esfriamento à temperatura de $5-10{ }^{\circ} \mathrm{C}$ por um período de cinco dias. Antes da montagem dos tratamentos foi realizado o tratamento sanitário, as sementes foram colocadas em solução de hipoclorito de sódio a $3 \%$ por cinco minutos e, em seguida, lavadas com o auxílio de uma peneira com água corrente destilada.

$O$ teste de germinação foi conduzido com folhas de papel do tipo germitest ${ }^{\Theta}$, onde os papéis foram previamente umedecidos com água destilada em uma quantidade de 2,5 vezes o peso do papel, conforme descrito nas Regras para Análise de Sementes - RAS (BRASIL 2009). 
Tabela 1. Caracterização da pureza física e porcentagem de germinação das espécies Panicum maximum cv. Aruana, Panicum maximum cv. BRS Tanzânia, Brachiaria humidicola cv. BRS Tupi.

Table 1. Characterization of the physical purity and germination percentage of Panicum maximum cv. Aruana, Panicum maximum cv. BRS Tanzânia, Brachiaria humidicola cv. BRS Tupi.

\begin{tabular}{ccc}
\hline Espécie & Porcentagem de pureza & Porcentagem de germinação \\
\cline { 2 - 3 } & & $\%$ \\
P. maximum cv. Aruana & 40 & 53 \\
P. maximum cv. Tanzânia & 94 & 77 \\
B. humidicola cv. BRS Tupi & 71 & 75 \\
\hline
\end{tabular}

Para todos os testes foram utilizadas 25 sementes como unidade experimental em seis repetições, adotou-se o delineamento inteiramente casualizado. Logo em seguida, as sementes foram acondicionadas em um germinador do tipo Mangelsdorf ${ }^{\circledR}$ em temperatura constante de $20^{\circ} \mathrm{C}$ com iluminação natural.

Os experimentos foram conduzidos em ausência $\left(0 \mathrm{mg} \mathrm{L}^{-1}\right)$ e na presença de 3,180 e $200 \mathrm{mg} \mathrm{L}^{-1}$ para $\mathrm{Cd}, \mathrm{Pb}$ e Cu , respectivamente, conforme os valores de investigação agrícola proposto pela Resolução no 420 do CONAMA (2009). Os sais utilizados foram Nitrato de Cádmio $\left(\mathrm{Cd}\left(\mathrm{NO}_{3}\right)_{2}\right)$, Nitrato de Chumbo $\left(\mathrm{Pb}\left(\mathrm{NO}_{3}\right)_{2}\right)$ e Nitrato de Cobre $\left(\mathrm{Cu}\left(\mathrm{NO}_{3}\right)_{2}\right)$.

No teste de germinação, foram consideradas germinadas as plântulas normais que obtiveram comprimento radicular superior a $5 \mathrm{~mm}$ e rompimento da plúmula. As contagens da germinação foram registradas a cada 24 horas até o vegésimo dia, neste foram realizadas as medições de raiz e parte aérea. Essas medidas foram utilizadas para os cálculos de germinação $(G)$, do índice de velocidade de germinação (IVG), do índice de vigor (IV) e do índice de tolerância (IT), segundo equações:

$$
\begin{aligned}
& \text { PG }(\%)=(\mathrm{n} / \mathrm{N}){ }^{*} 100 \\
& \text { IVG }=\sum(\mathrm{n} / \mathrm{t}) \\
& \text { IV }=\mathrm{CP}(\mathrm{cm}) \times \text { PG }(\%) \\
& \text { IT RA }(\%)=\mathrm{CRA}_{\mathrm{Pr}} / \mathrm{CRA}_{\text {Aus }}{ }^{*} 100 \\
& \text { IT PA }(\%)=\mathrm{CPA}_{\mathrm{Pr}} / \mathrm{CPA}_{\text {Aus }}{ }^{*} 100
\end{aligned}
$$

Onde PG é porcentagem de germinação; $n$ é o número de sementes germinadas normais; $\mathrm{N}$ é o número total de sementes; IVG é índice de velocidade de germinação; t é o número de dias decorridos entre a semeadura e a germinação (MAGUIRE 1962); IV é índice de vigor (DEZFULI et al. 2008), CP é o comprimento de plântula $(\mathrm{cm})$; IT RA (AHMAD et al. 2012) é índice de tolerância da raiz; $C R A_{P r}$ é média do comprimento da raiz na presença do elemento-traço; e $C R A_{\text {Aus }}$ média do comprimento da raiz na ausência do elemento-traço; IT PA (AHMAD et al. 2012) é índice de tolerância da parte aérea; CPA $A_{\operatorname{Pr}}$ é média do comprimento da parte aérea na presença do elemento-traço; e $\mathrm{CPA}_{\mathrm{Aus}}$ média do comprimento da parte aérea na ausência do elemento-traço;

Todos os dados obtidos foram submetidos à análise de variância $(p \leq 0,05)$, considerando arranjo fatorial dos tratamentos (espécies e elementos-traço). Quando constatada significância estatística, realizouse $o$ teste de Tukey $(p \leq 0,05)$ para verificar a magnitude da diferença entre tratamentos. Para a análise estatística, os dados de porcentagem de germinação foram transformados para arcsen $\sqrt{ } \mathrm{x} / 100$ e os dados do teor dos elementos-traço foram analisados após transformação logarítmica, $Y=\log (X+1)$.

\section{RESULTADOS E DISCUSSÃO}

Neste estudo observou-se que dos três elementos-traço utilizados o que mais afetou a germinação foi - $\mathrm{Cu}$, sendo que, a dose utilizada é igual ao valor orientador de investigação agrícola proposto pela Resolução no 420 do CONAMA (2009).

Quando da presença do Cu na dose de $200 \mathrm{mg} \mathrm{L}^{-1}$ ocorreu a inibição da germinação, emissão de PA (Tabela 2) e RA (Tabela 3) para a espécie P. maximum cv. Aruana. Na ausência do Cu a mesma cultivar apresentou PG de 53\%, PA com $1,75 \mathrm{~cm}$ e IV de 70.

A presença do Cu resultou em redução PG, PA e IV (Tabela 2) para a cultivar Tanzânia e $B$. humidicola. Para $B$. humidicola na ausência de Cu o valor de germinação obtido foi $75 \%$, enquanto que, na dose de $200 \mathrm{mg} \mathrm{L}^{-1}$ houve uma redução na porcentagem de germinação para $35 \%$ (Tabela 2). A cultivar Tanzânia apresentou comportamento semelhante a B. humidicola, onde PG, comprimento de PA e IV diminuíram de $77 \%, 3,41 \mathrm{~cm}$ e 128 na ausência do $\mathrm{Cu}$ para $9 \%, 0,36 \mathrm{~cm}$ e 3,2, respectivamente, na presença do elemento-traço (Tabela 2). 
Tabela 2. Porcentagem de germinação (PG), comprimento de parte aérea (PA) e índice de vigor (IV) para as espécies Panicum maximum cv. Aruana, Panicum maximum cv. BRS Tanzânia, Brachiaria humidicola cv. BRS Tupi na ausência $\left(0 \mathrm{mg} \mathrm{L}^{-1}\right)$ e presença de $\mathrm{Cu}\left(200 \mathrm{mg} \mathrm{L}^{-1}\right)$.

Table 2. Germination percentage (PG), shoot length (PA) and vigor index (IV) to species Panicum maximum cv. Aruana, Panicum maximum cv. BRS Tanzânia, Brachiaria humidicola cv. BRS Tupi in in the absence $\left(0 \mathrm{mg} \mathrm{L}^{-1}\right)$ and in the presence of $\mathrm{Cu}\left(200 \mathrm{mg} \mathrm{L}^{-1}\right)$.

\begin{tabular}{lcccccc}
\hline \multicolumn{1}{c}{ Espécie } & \multicolumn{2}{c}{ PG } & \multicolumn{2}{c}{ PA } & \multicolumn{2}{c}{ IV } \\
& $-----c m---$ & & \\
\hline & $0 \mathrm{mg} \mathrm{L}^{-1}$ & $200 \mathrm{mg} \mathrm{L}^{-1}$ & $0 \mathrm{mg} \mathrm{L}^{-1}$ & $200 \mathrm{mg} \mathrm{L}^{-1}$ & $0 \mathrm{mg} \mathrm{L}^{-1}$ & $200 \mathrm{mg} \mathrm{L}^{-1}$ \\
\cline { 2 - 7 } P. maximum cv. Aruana & $53 \mathrm{Ab}$ & $0,0 \mathrm{Bb}$ & $1,75 \mathrm{Ab}$ & $0,0 \mathrm{Bb}$ & $70 \mathrm{Ab}$ & $0 \mathrm{Bc}$ \\
P. maximum cv. Tanzânia & $77 \mathrm{Aa}$ & $9,0 \mathrm{Bb}$ & $3,41 \mathrm{Aa}$ & $0,36 \mathrm{Bb}$ & $128 \mathrm{Aa}$ & $3,2 \mathrm{Bb}$ \\
B. humidicola cv. BRS Tupi & $75 \mathrm{Aa}$ & $35 \mathrm{Bb}$ & $3,35 \mathrm{Aa}$ & $1,46 \mathrm{Ba}$ & $113 \mathrm{Aa}$ & $51 \mathrm{Ba}$ \\
\hline
\end{tabular}

Letras maiúsculas comparam médias doses dentro de espécies e letras minúsculas compararam espécies dentro de doses pelo teste de Tukey $(p \leq 0,05)$.

Tabela 3. Média das três espécies para Índice de Velocidade de Germinação (IVG) e comprimento de raiz (RA) na ausência $\left(0 \mathrm{mg} \mathrm{L}^{-1}\right)$ e presença de $\mathrm{Cu}\left(200 \mathrm{mg} \mathrm{L}^{-1}\right)$.

Table 3. Average of the three species for Germination speed index (GSI) and root length in the absence (0 $\left.\mathrm{mg} \mathrm{L}^{-1}\right)$ and in the presence of $\mathrm{Cu}\left(200 \mathrm{mg} \mathrm{L}^{-1}\right)$.

\begin{tabular}{lll}
\hline Dose $\left(\mathrm{mg} \mathrm{L}^{-1}\right)$ & $\mathrm{IVG}$ & $\mathrm{RA}(\mathrm{cm})$ \\
\hline 0 & $16,9 \mathrm{a}$ & $2,7 \mathrm{a}$ \\
200 & $1,6 \mathrm{~b}$ & $0 \mathrm{~b}$ \\
\hline
\end{tabular}

Letras minúsculas comparam doses de $\mathrm{Cu}$. Teste de Tukey $(p \leq 0,05)$

O efeito do Cu sobre a germinação foi estudado por BORGES et al. (2016) e STEFANELLO et al. (2018). BORGES et al. (2016) avaliaram a germinação das espécies Brachiaria decumbens e Brachiaria brizantha (cv. Piatã, Marandu, MG 5) na ausência e presença de $\mathrm{Cu}\left(200 \mathrm{mg} \mathrm{L}^{-1}\right)$. Esses autores observaram que a presença do $\mathrm{Cu}$ resultou em redução na PG para todas as espécies estudadas, entretanto, a espécie mais afetada pela presença do Cu foi $B$. decumbens, com uma redução de $99 \%$ da PG na presença do $\mathrm{Cu}$, em comparação ao controle. STEFANELLO et al. (2018) avaliaram a tolerância das sementes de chia ao $\mathrm{Cu}$. Os autores observaram que o aumento da concentração de $\mathrm{Cu}(0,60,120,180 \mathrm{e}$ $240 \mathrm{mg} \mathrm{L}^{-1}$ ) promoveu decréscimo significativo na germinação das sementes, no crescimento e na massa seca das plântulas de chia. $\mathrm{O}$ aumento da concentração de $\mathrm{Cu}$ em teste de germinação conduzido por DRAB et al. (2011) resultou em diminuição na porcentagem de germinação para centeio (Secale cereale L.), trigo (Triticum aestivum L.), colza (Brassica napus oleifera L.) e mostarda branca (Sinapis alba EU.).

O cobre, quando em níveis tóxicos, interfere no processo de germinação, afetando a atividade enzimática, podendo alterar o DNA, causando oxidação de proteínas, e danos às membranas plasmáticas (TEWARI et al. 2006). MURPHY et al. (1999), destacam que níveis tóxicos de Cu podem provocar a peroxidação lipídica, resultando em danos às membranas plasmáticas diminuindo a absorção e o potencial osmótico e, consequentemente, diminuindo a expansão celular. O Cu pode bloquear a absorção de água inibindo a germinação (KRANNER \& COLVILLE 2011), e o transporte de elétrons e o metabolismo primário da semente, assim não ocorrendo o processo de germinação (WILLIAMS 2015).

Para as variáveis IVG e RA ocorreu apenas efeito de dose de $\mathrm{Cu}$, sendo que, a presença de $\mathrm{Cu}$ resultou em redução do IVG em dez vezes e inibiu a emissão de raiz (Tabela 3). As espécies de gramíneas estudadas por BORGES et al. (2016) não apresentaram inibição de emissão de raiz, o que sugere, que as espécies avaliadas no presente estudo são menos tolerantes ao $\mathrm{Cu}$.

O comprimento radicular é parâmetro importante quando da avaliação do efeito do elemento-traço, pois, a radícula é o primeiro órgão da plântula que entra em contato com a solução contaminada (FENG et al. 2016). Em estudos com áreas contaminadas com Cu, GIROTTO et al. (2014) observaram reduções de matéria seca tanto da raiz quanto da parte aérea e clorose internerval para Avena stringosa.

A presença do chumbo afetou as cultivares Aruana e Tanzânia e, ao contrário, não afetou a $B$. humidicola. O comprimento de PA da Aruana reduziu de $2,7 \mathrm{~cm}$ na ausência de $\mathrm{Pb}$ para $1,9 \mathrm{~cm}$ na presença (Tabela 4). Para Tanzânia houve redução do comprimento de RA e IV na presença do Pb. Não houve interação significativa entre espécie e doses de Pb para as variáveis G e IVG. 
Tabela 4. Comprimento de raiz (RA), comprimento de parte aérea (PA) e índice de vigor (IV) para Panicum maximum cv. Aruana, Panicum maximum cv. BRS Tanzânia, Brachiaria humidicola cv. BRS Tupi na ausência $\left(0 \mathrm{mg} \mathrm{L}^{-1}\right)$ e presença de $\mathrm{Pb}\left(180 \mathrm{mg} \mathrm{L}^{-1}\right)$.

Table 4. Root length (RA), aerial part (AP) length and vigor index (VI) to species Panicum maximum cv. Aruana, Panicum maximum cv. BRS Tanzânia, Brachiaria humidicola cv. BRS Tupi in the absence $\left(0 \mathrm{mg} \mathrm{L}^{-1}\right)$ and in the presence of $\mathrm{Pb}\left(180 \mathrm{mg} \mathrm{L}^{-1}\right)$.

\begin{tabular}{|c|c|c|c|c|c|c|}
\hline \multirow[t]{2}{*}{ Espécie } & \multicolumn{2}{|c|}{ RA } & \multicolumn{2}{|c|}{ PA } & \multicolumn{2}{|c|}{ IV } \\
\hline & & - n n n n & & ---- & & \\
\hline & $0 \mathrm{mg} \mathrm{L}^{-1}$ & $180 \mathrm{mg} \mathrm{L}^{-1}$ & $0 \mathrm{mg} \mathrm{L}^{-1}$ & $180 \mathrm{mg} \mathrm{L}^{-1}$ & $0 \mathrm{mg} \mathrm{L}^{-1}$ & $180 \mathrm{mg} \mathrm{L}^{-1}$ \\
\hline P. maximum cv. Aruana & $3,5 \mathrm{Aa}$ & 3,8 Aa & $2,7 \mathrm{Aa}$ & $1,9 \mathrm{Bb}$ & $157 \mathrm{Aa}$ & $152 \mathrm{Aa}$ \\
\hline P. maximum cv. Tanzânia & 3,8 Aa & $1,4 \mathrm{Bb}$ & $3,1 \mathrm{Aa}$ & $2,4 \mathrm{Aa}$ & $166 \mathrm{Aa}$ & $75 \mathrm{Ab}$ \\
\hline B. humidicola cv. BRS Tupi & $2,5 \mathrm{Aa}$ & 3,2 Aa & $3,1 \mathrm{Aa}$ & 3,9 Aa & $101 \mathrm{Aa}$ & $159 \mathrm{Aa}$ \\
\hline
\end{tabular}

Letras maiúsculas comparam médias das espécies dentro de doses e letras minúsculas comparam médias das doses dentro de espécies pelo teste de Tukey $(p \leq 0,05)$.

A redução do comprimento da RA e no IV também foi observada para as espécies Brachiaria decumbens e Brachiaria brizantha (cv. Piatã, Marandu, MG 5) na presença de $\mathrm{Pb}$ (180 mg L ${ }^{-1}$ ) (BORGES et al. 2016). O efeito do $\mathrm{Pb}$ na germinação e desenvolvimento das plântulas das espécies aveia preta (Avena stringosa) e nabo forrageiro (Raphanus sativus) foi avaliado por BORGES et al. (2019). Os autores observaram reduções da PG, do IVG e IV para a aveia preta na presença de $200 \mathrm{mg} \mathrm{L}^{-1}$ de $\mathrm{Pb}$, enquanto que para nabo forrageiro a $P G$ e o IVG não foram afetados pela presença do elemento-traço.

SOUZA et al. (2011) e SILVA et al. (2013) afirmam que plantas cultivadas em ambientes contaminados com $\mathrm{Pb}$ podem ter germinação inibida ou redução do crescimento das raízes e alteração do metabolismo da planta. Nesta fase, a exposição ao $\mathrm{Pb}$ pode causar disfunções morfológicas, fisiológicas e bioquímicas (ZUKOWSKA \& BIZIUK 2008, SHAH et al. 2010, SHAHID et al. 2011).

A fitotoxicidade de cinco concentrações de chumbo $(0,0 ; 0,5 ; 1,0 ; 2,0$ e $5,0 \mathrm{mM})$ na germinação, anatomia radicular, e divisão celular de alface foi avaliada por PEREIRA et al. (2013), sendo que a germinação das sementes e o crescimento inicial das plântulas foram reduzidos proporcionalmente ao aumento nas concentrações de $\mathrm{Pb}$. A anatomia radicular apresentou reduções nas barreiras apoplásticas e modificações do xilema relacionadas com um aumento na condutividade hidráulica na presença de $\mathrm{Pb}$. Os autores observaram que o sistema radicular da alface foi mais afetado que a parte aérea pelas doses de chumbo, assim como o observado para as cultivares Aruana e Tanzânia, no presente trabalho. Eles relacionaram os sintomas de fitotoxicidade com a redução no índice mitótico do meristema apical radicular e maior condução de chumbo para a parte aérea.

Para cádmio não houve interação entre espécie/cultivares e doses de $\mathrm{Cd}$. A presença do Cd reduziu $P G$, IVG e comprimento de PA de $64 \%, 17,8$ e $3,67 \mathrm{~cm}$ para $56 \%, 12,5$ e 2,88 cm, respectivamente, entretanto, não afetou RA e IV (Tabela 5). O efeito de elementos-traço, como $\mathrm{Cd}$, na germinação das sementes depende da capacidade de atingir os tecidos embrionários através das barreiras fisiológicas, como os do revestimento das sementes (AKINCI \& AKINCI 2010, KO et al. 2012).

Tabela 5. Média para três espécies para porcentagem de germinação (PG), índice de velocidade de germinação (IVG), comprimento de raiz (RA) e parte aérea (PA) e índice de vigor (IV) na ausência $\left(0 \mathrm{mg} \mathrm{L}^{-1}\right)$ e presença de $\mathrm{Cd}\left(3 \mathrm{mg} \mathrm{L}^{-1}\right)$.

Table 5. Average of the three species for germination percentage (G), germination speed index (GSI), root length $(R A)$ and aerial part $(A P)$, and vigor index $(V I)$ in the absence $\left(0 \mathrm{mg} \mathrm{L}^{-1}\right)$ and in the presence of $\mathrm{Cd}\left(3 \mathrm{mg} \mathrm{L}^{-1}\right)$.

\begin{tabular}{|c|c|c|c|c|c|}
\hline Dose & $P G$ & IVG & RA & PA & IV \\
\hline & $\%$ & & ------- & ------ & \\
\hline $0 \mathrm{mg} \mathrm{L}^{-1}$ & $64 a$ & $17,8 \mathrm{a}$ & $3,88 a$ & $3,67 a$ & $145 a$ \\
\hline $3 \mathrm{mg} \mathrm{L}^{-1}$ & $56 \mathrm{~b}$ & $12,5 b$ & $4,46 a$ & $2,88 b$ & $134 \mathrm{a}$ \\
\hline
\end{tabular}

BORGES et.al. (2016), em estudo observaram redução do comprimento de raiz do Cd para cv. Piatã, $B$. brizantha e na $B$. decumbens, entretanto para as cultivares marandu e MG 5 não houve redução corroborando com os resultados obtidos no presente estudo.

Em estudo com Raphanus sativus na presença e ausência de Cd, BORGES et al. (2019), observaram 
redução no comprimento radicular na presença do elemento-traço. Outros autores também observaram esse fenômeno em ervilha (CHUGH \& SAWHNEY 1996) e em camomila (SADERI \& ZARINKAMAR 2012). Em concentrações tóxicas, os elementos-traço como o $\mathrm{Cd}$ podem interromper a divisão celular, o processo de replicação do RNA, o processo de reparação do DNA ao desenvolvimento da planta (MOOSAVI et al. 2012).

Em ensaio sobre o efeito do Cd na germinação da ervilha (Pisum sativum cv. Bonneville), CHUGH \& SAWHNEY (1996) observaram que o crescimento do eixo embrionário foi significativamente inibido por níveis tão baixos quanto $0,25 \mathrm{Mm}$ de cádmio e o alongamento da radícula foi afetado mais severamente que o da plúmula. Esses autores observaram também que a atividade amilolítica total, assim como as atividades das a e $\beta$-amilases, diminuíram com o aumento da concentração do elemento-traço no meio. $O$ efeito do cádmio na mobilização do amido e na atividade respiratória resultou em efeitos adversos sobre a germinação. O mesmo efeito do $\mathrm{Cd}$ na germinação e no eixo embrionário foi observado por SFAXIBOUSBIH et al. (2010) para feijão (Phaseolus vulgaris).

A ausência de interação espécie e doses de Cd e as diferenças significativas entre espécies para PG, PA, IV e IVG (Tabela 5) podem estar relacionadas as peculiaridades de cada planta. Segundo, MUNZUROGLU \& GECKIL (2002) existem diferentes estruturas e revestimentos na anatomia da semente, e assim a mesma concentração de elemento-traço pode ter efeitos diferentes em cada espécie avaliada.

$\mathrm{A}$ análise da Figura 1 resulta em dois cenários, o primeiro para $\mathrm{Cu}$ para $\mathrm{O}$ qual a ordem de sensibilidade é IT RA > IT PA, enquanto que para Cd e Pb ocorre o oposto, ou seja, IT PA > IT RA. GUTERRES et al. (2019) avaliando o efeito do As, Cd, Cr e Pb na germinação de Astrebla lappacea, Themeda australis, Austrostipa scabra e Acacia harpophylla observaram que o IT RA foi o melhor indicador de sensibilidade quando comparado ao IT PA, colaborando com o observado no presente estudo para Cu.
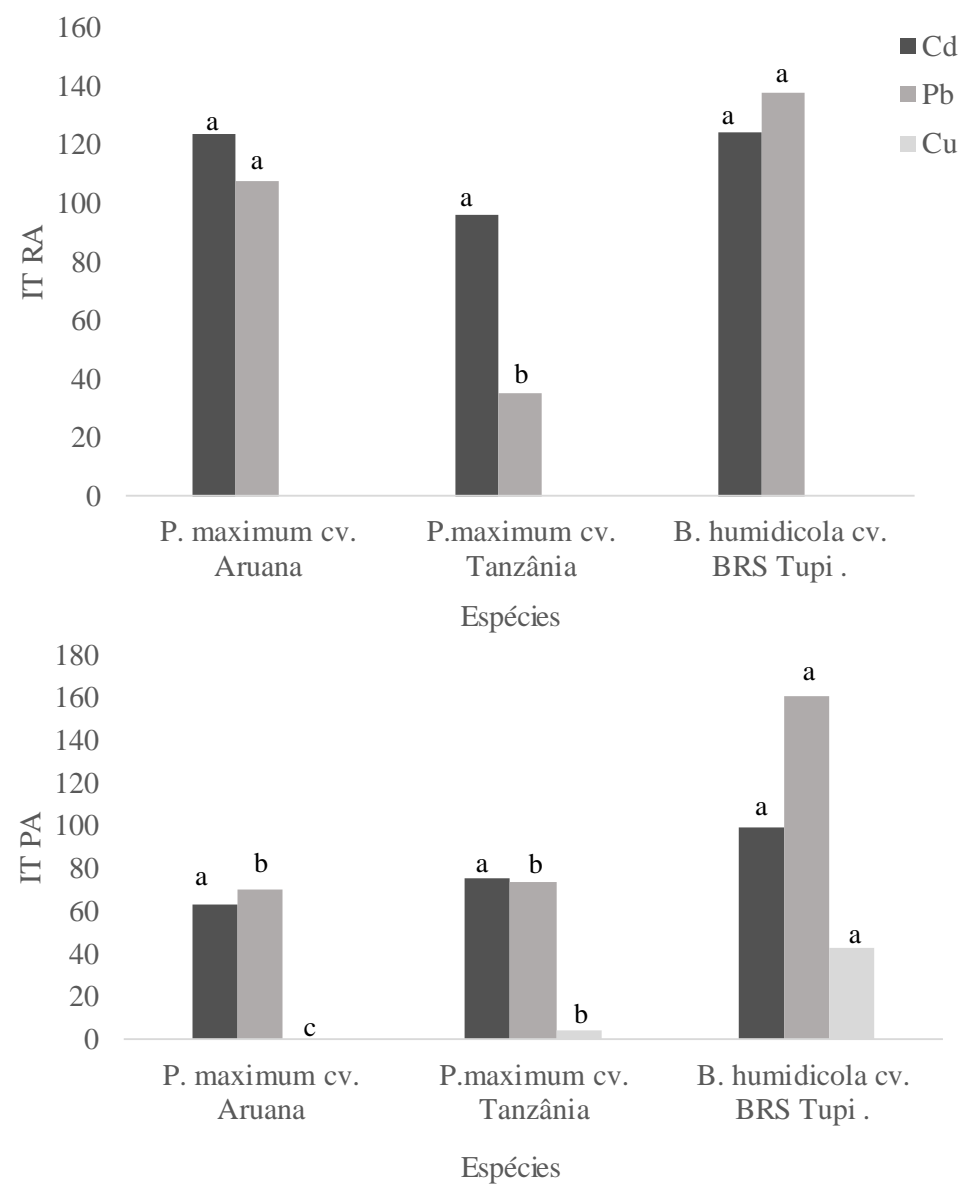

Figura 1. Índice de tolerância da parte aérea (IT PA) e da raiz (RA) para as espécies Panicum maximum cv. Aruana, Panicum maximum cv. BRS Tanzânia, Brachiaria humidicola cv. BRS Tupi. Letras minúsculas estatisticamente comparam espécies dentro de elemento-traço, teste de Tukey $(p \leq 0,05)$.

Figure 1. Aerial part tolerance index (AP TI) and of the root (R TI) of the species Panicum maximum $\mathrm{cV}$. Aruana, Panicum maximum cv. BRS Tanzânia, Brachiaria humidicola cv. BRS Tupi. Lowercase letters statistically compare species within the same trace element, Tukey test $(p \leq 0.05)$. 
AHMAD et al. (2012), avaliaram o efeito de doses crescentes de $\mathrm{Cd}\left(0,5,20,50\right.$ e $\left.80 \mathrm{mg} \mathrm{L}^{-1}\right)$ na germinação de cultivares de trigo e observaram que na dose de $5 \mathrm{mg} \mathrm{L}^{-1}$ as cultivares apresentaram IT RA superior a $80 \%$ e que a redução ocorreu a partir da dose $20 \mathrm{mg} \mathrm{L}^{-1}$.

Porcentagem de germinação, índice de vigor e o índice de tolerância podem ser considerados parâmetros que indicam a capacidade de resposta das plantas ao estresse promovido por substratos contaminados. Para GUTERRES et al. (2019) esses parâmetros podem ajudar na seleção de plantas para projetos de recuperação de áreas contaminadas.

A análise dos índices de tolerância (Figura 1) e da porcentagem de germinação (Tabelas 2 e 5) indicam que a espécie $P$. maximum cv. Aruana teve uma ausência de germinação pela presença do elemento-traço, portanto, não seria uma espécie promissora para fitorremediação ou fitoestabilização de áreas contaminadas com os elementos-traço $\mathrm{Cd}$, $\mathrm{Cu}$ e $\mathrm{Pb}$. Além do mais, na presença do $\mathrm{Cu}$ nenhuma das três espécies avaliadas no presente estudo poderiam ser utilizadas em projetos de recuperação.

Os índices de tolerância (Figura 1), porcentagem de germinação (Tabela 5) e índice de vigor (Tabelas 2 e 4) obtidos para $\mathrm{Cd}$ e $\mathrm{Pb}$ indicam que a espécie mais promissora para compor projetos de recuperação de áreas contaminadas por $\mathrm{Pb}$ e $\mathrm{Cd}$ seria a $B$. humidicola cv. BRS Tupi.

\section{CONCLUSÃO} Aruana.

A presença do Cu inibiu a germinação, emissão de raiz e parte aérea da espécie $P$. maximum cv.

A porcentagem de germinação, comprimento de parte aérea e índice de vigor foram afetadas pela presença do Cu e Cd para as espécies $P$. maximum cv. Tanzânia e B. humidicola cv. BRS Tupi.

A presença do $\mathrm{Pb}$ afetou comprimento de parte aérea e de raiz, e índice de vigor para $P$. maximum cultivares Aruana e Tanzânia, enquanto que, a espécie $B$. humidicola cv. BRS Tupi não foi afetada.

A ordem decrescente de sensibilidade das espécies na presença de $\mathrm{Cd}$ e $\mathrm{Pb}$ foi $P$. maximum $\mathrm{cv}$. Aruana $>$ P. maximum cv. Tanzânia $>B$. humidicola cv. Tupi.

A espécie mais promissora para uso em recuperação de áreas contaminadas com $\mathrm{Cd}$ e $\mathrm{Pb}$ seria a $B$. humidicola cv. BRS Tupi.

\section{AGRADECIMENTOS}

Os autores agradecem a Coordenação de Aperfeiçoamento de Pessoal de Nível Superior (CAPES), a Fundação de Amparo à Pesquisa e Inovação do Estado de Santa Catarina (FAPESC) e a Universidade do Estado de Santa Catarina (UDESC) pelo apoio financeiro.

\section{REFERÊNCIAS}

AKINCI IE \& AKINCI S. 2010. Effect of chromium toxicity on germination and early seedling growth in melon (Cucumis melo L.). African Journal of Biotechnology 9: 4589-4594.

AHMAD I et al. 2012. Effect of cadmium on seed germination and seedling growth of four wheats (Triticum aestivum L.) cultivars. Pakistan Journal of Botany 44: 1569-1574.

ÁLVAREZ-MATEOS $P$ et al. 2019. Phytoremediation of highly contaminated mining soils by Jatropha curcas L. and production of catalytic carbons from the generated biomass. Journal of Environmental Management 231: 886-895.

BORGES KSC et al. 2016. Germination and initial development of Brachiaria brizantha and Brachiaria decumbens on exposure to cadmium, lead and copper. Journal of Seed Sciences 38: 335-343.

BORGES KSC et al. 2019. Damage on the germination and development of radish seedlings and oat exposure to cadmium and lead. In: SEABRA G. (Ed). Conferência da Terra: Habitats urbanos e rurais. Ituiutaba: Barlavento. p.533542.

BRASIL. 2009. Regras para análise de sementes. Ministério da Agricultura, Pecuária e Abastecimento. Secretaria de Defesa Agropecuária. Brasília: MAPA. 399p.

CHEN L et al. 2014. Interaction of hyperaccumulator Solanum nigrum L. and functional endophyte Pseudomonas sp. Lk9 on soil heavy metals uptake. Soil Biology and Biochemistry 68: 300-308.

CHUGH LK \& SAWHNEY SK 1996. Effect of cadmium on germination, amylases and rate of respiration of germinating pea seeds. Environmental Pollution 92: 1-5.

CONAMA. 2009. Conselho Nacional do Meio Ambiente. RESOLUÇÃO Nº 420, de 28 de dezembro de 2009.

CORREA LA \& SANTOS PM. 2003. Manejo e utilização de plantas forrageiras dos gêneros Panicum, Brachiaria e Cynodon. São Carlos: Embrapa Pecuária Sudeste. 36p.

CORREIA NM \& PERUSSI FJ. 2015. Manejo de plantas adultas de Panicum maximum cv. Aruana. Revista Brasileira de Ciências Agrárias 10: 91-96.

DEZFULI PM et al. 2008. Influence of priming techniques on seed germination behavior of maize inbred lines (Zea mays L.) ARPN Journal of Agricultural and Biological Science. 3: 22-25. 
DRAB M et al. 2011. Seed germination of selected plants under the influence of heavy metals. Civil and Environmental Engineering Reports 7: 47-57.

FENG $R$ et al. 2016. Responses of root growth and antioxidative systems of paddy rice exposed to antimony and selenium. Envionmental and Experimental Botany 122: 29-38.

GIROTTO E et al. 2014. Copper availability assessment of Cu-contaminated vineyard soils using black oat cultivation and chemical extractants. Environmental Monitoring and Assessment 186: 9051-9063.

GONÇALVES LC \& BORGES I. 2006. Tópicos de forragicultura tropical. Belo Horizonte: FEPMVZ. 117p.

GUTERRES $\mathrm{J}$ et al. 2019. Assessing germination characteristics of Australian native plant species in metal/metalloid solution. Journal of Hazardous Materials 364: 173-181.

KABATA-PENDIAS A. 2011. Trace elements in soils and plants. 4.ed. Boca Raton: CRC Press 520p.

KRANNER I \& COLVILLE L. 2011. Metals and seeds: Biochemical and molecular implications and their significance for seed germination. Environmental and Experimental Botany 72: 93-105.

KO KS et al. 2012. Evaluation of the toxic effects of arsenite, chromate, cadmium, and copper using a battery of four bioassays. Applied Microbiology and Biotechnology 95: 1343-1350.

LAMBRECHTS T et al. 2014. Comparative analysis of Cd and Zn impacts on root distribution and morphology of Lolium perenne and Trifolium repens: implications for phytostabilization. Plant and Soil 376: 229-244.

MADEJÓN P et al. 2015. Effects of soil contamination by trace elements on white poplar progeny: seed germination and seedling vigour. Environmental Monitoring and Assessment 187: 663-674.

MAGUIRE JD. 1962. Speed of germination: aid in selection and evaluation for seedling emergence and vigor. Crop Science 2: 176-177.

MIDHAT L et al. 2019. Accumulation of heavy metals in metallophytes from three mining sites (Southern Centre Morocco) and evaluation of their phytoremediation potential. Ecotoxicology and Environmental Safety 169: 150-160.

MOOSAVI S et al. 2012. Effects of some heavy metals on seed germination characteristics of canola (Barassica napus), wheat (Triticum aestivum) and safflower (Carthamus tinctorious) to evaluate phytoremediation potential of these crops. Journal of Agricultural Science 4: 1-19.

MUNZUROGLU O \& GECKIL H. 2002. Effects of element-trace on seed germination, root elongation, and coleoptile and hypocotyl growth in Triticum aestivum and Cucumis sativus. Archives Environmental Contamination and Toxicology 43: 203-213.

MURPHY AS et al. 1999. Early copper- induced leakage of $\mathrm{K}+$ from Arabidopsis seedlings is mediated by ion channels and coupled to citrate efflux. Plant Physiology 121: 1375-1382.

PEREIRA AR 2006. Como selecionar plantas para áreas degradadas e controle de erosão. Belo Horizonte: FAPI. 70p.

PEREIRA PM et. al. 2013. Fitotoxicidade do chumbo na germinação e crescimento inicial de alface em função da anatomia radicular e ciclo celular. Revista Agro@mbiente On-line 7: 36-43.

SANTOS FS et al. 2005. Fitorremeadição por Brachiaria humidicola de área de disposição de um resíduo perigoso. Floresta e Ambiente 12: 22-29.

SADERI SZ \& ZARINKAMAR F. 2012. The effect of different Pb and Cd concentrations on seed germination and seedling growth of Matricaria chamomilla. Advances in Environmental Biology 6: 1940-1943.

SFAXI-BOUSBIH A et al. 2010. Cadmium impairs mineral and carbohydrate mobilization during the germination of bean seeds. Ecotoxicology and Environmental Safety 73: 1123-1129.

SHAH FUR et al. 2010. Heavy Metals Toxicity in Plants. In: ASHRAF M et al. (Ed.). Plant Adaptation and Phytoremediation. Nova York: Springer. p.71-97

SHAHID M et al. 2011. Lead-induced geno-toxicity to Vicia faba L. roots in relation with metal cell uptake and initial speciation. Ecotoxicology and Environmental Safety 74: 78-84.

SILVA PCC et al. 2013. Crescimento de plantas de girassol cultivadas em ambiente contaminado por chumbo. Bioscience Journal 29: 1576-1586.

SOUZA EL et al. 2018. Plantas forrageiras para pastos de alta produtividade. Nutritime 15: 8273-8284.

SOUZA LA et al. 2011. Tolerância e potencial fitorremediador de Stizolobium aterrimum associada ao fungo micorrízico arbuscular Glomus etunicatum em solo contaminado por chumbo. Revista Brasileira de Ciência Solo 35: $1441-1451$.

STEFANELLO R et al. 2018. Tolerance of chia seeds to copper. Acta Biológica Catarinense 5: 42-49.

TEWARI RK et al. 2006. Antioxidant responses to enhanced generation of superoxide anion radical and hydrogen peroxide in the copper-stressed mulberry plants. Planta 223: 1145-1153.

WILLIAMS ME. 2015. Plant Nutrition 3: Micronutrients and metals. The Plant Cell 27: 1-20.

YADA MM et al. 2015. Atributos Químicos e Bioquímicos em Solos Degradados por Mineração de Estanho e em Fase de Recuperação em Ecossistema Amazônico. Revista Brasileira de Ciência do Solo 39: 714-724.

ZUKOWSKA J \& BIZIUK M. 2008. Methodological evaluation of method for dietary heavy metal intake. Journal of Food Science 73: 21-29. 